\title{
The semantics of habituality as an argument for event-mediated quantification*
}

\author{
Sascha Alexeyenko \\ University of Göttingen
}

\begin{abstract}
The goals of this paper are two-fold. On the one hand, it has as its aim an analysis of the semantics of habituality in the framework of event semantics. In particular, it will be argued that a proper treatment of habituality must minimally meet the following desiderata: (a) allow a unified analysis of the habitual and the progressive as different subtypes of the imperfective, (b) work both for bare habituals and for habituals that contain certain kinds of quantificational elements, and (c) be able to model the scope behavior of indefinites in habituals of both types. Based on various existing proposals, an analysis along these lines will be put forward and formalized. On the other hand, the paper also seeks to show that a habitual semantics that meets these desiderata cannot be implemented in combination with a classical GQ analysis of quantificational DPs, but follows without any additional stipulations if an event-based approach to quantification is adopted. Thus, habituals provide a further argument in favor of modeling distributive quantification with the mediation of events.
\end{abstract}

Keywords: event semantics, generalized quantifiers, habituals, indefinites, Q-adverbs

\section{Introduction}

This paper seeks to bridge two empirical and theoretical domains in event semantics that have otherwise been considered largely in isolation from each other: habituality and quantification. While there has been a lot of fruitful research in both of these areas, the insights gained in each one of them have not been used much as a means to inform and constrain the theories developed in the respective other. Hence, in what follows, I will first briefly outline some prominent lines of research in each of these areas in order to highlight some immediate connection points between them.

* For comments on various stages and versions of this paper, I would like to thank Sam Al Khatib, Lucas Champollion, Danny Fox, Martin Hackl, Irene Heim, Graham Katz, Jan Köpping, Manuel Križ, Clemens Mayr, Louise McNally, Cécile Meier, Viola Schmitt, Roger Schwarzschild, Anna Szabolcsi, Carla Umbach, Hedde Zeijlstra, as well as the audiences of SuB22 in Potsdam/Berlin, SALT28 at MIT, the NYU Semantics Group, and the MIT Ling-Lunch. I am particularly grateful to Gennaro Chierchia, Fred Landman, Susan Rothstein, and Ede Zimmermann for extensive discussions about this work. 
The semantics of habituality as an argument for event-mediated quantification

An important branch of work in the domain of quantification within the framework of event semantics has concerned the foundational question of how the semantics of core quantificational elements should be modeled in event-based systems. In this respect, the main opposition here has been between adhering to the classical theory of generalized quantifiers (GQT; Barwise \& Cooper 1981; Keenan \& Stavi 1986) implemented in an event-semantic setting (e.g. Landman 2000) and adopting an alternative approach that models distributive quantification with the mediation of events.

The event-mediated theory of quantification (EMT), as I will call it in this paper, goes back to the work of Taylor (1985) and Schein (1993) and has emerged as a serious competitor to GQT, since it appears to have a broader empirical coverage. In particular, unlike classical GQT integrated into event semantics, it can easily account for adverbs like unharmoniously in (1) and for the available readings of sentences like in (2).

(1) Unharmoniously, every organ student sustained a note on the Wurlitzer for sixteen measures.

(2) Three video games taught every quarterback two new plays.

The problem that both of these examples from Schein 1993 present for event semantics in combination with GQT has to do with the unavailability in the logical form of an event variable that ranges over sum events composed of the individual events of sustaining a note in (1) and teaching in (2). It is only such a plural event that can be modified by an adverb like unharmoniously (as compared to, e.g., softly) and that makes it possible to model in a straightforward way the mixed cumulativedistributive reading of (2), according to which three video games is interpreted cumulatively, while every quarterback is interpreted distributively with respect to two new plays (both of these matters will be discussed in more detail in section 2).

By contrast, GQT and EMT are usually assumed to be on a par with respect to their capacity to account for the obligatorily narrow scope of the event quantifier vis-à-vis other quantifiers, as can be seen in examples like (3), where the universal must distribute over events of kissing.

(3) John kissed every girl.

In fact, however, what (3) demonstrates is not that the event quantifier generally must take narrow scope, but rather that specifically the existential event quantifier is required to do so. This is not unnecessary over-precision, as the examples in (1-3) are quite representative in showing that the discussion in connection with the choice between GQT and EMT has mainly concentrated on episodic perfective cases. As a matter of fact, however, it has long been observed in the literature on genericity 
that habituals, if thought of as instances of non-existential, quasi-universal event quantification, exhibit a narrow-scope requirement analogous to the one found in (3). This can be seen in an example like (4), in which the indefinite must take high scope over the habitual event quantifier (hence the pragmatic infelicity), in contrast to the minimally different example with an adverb of quantification in (5), where a narrow scope of the indefinite is possible.

(4) \#John smokes a cigarette without a filter.

(5) John often smokes a cigarette without a filter.

Conversely, the examples in (4-5) show that quantificational elements play an important role for developing an adequate theory of the semantics of habituals, yet questions related to the modeling of quantification in event semantics have usually not been considered as a factor in the semantic modeling of habituality.

The present paper aims to explore habituality and quantification in connection to each other. More concretely, it will be shown that, even though GQT and EMT fare equally well in accounting for the low scope of the event quantifier in episodic sentences like (3), they are not on a par with respect to modeling scope relations in habitual sentences such as (4) and (5). We will see that an adequate theory of the semantics of the habitual aspect forces us to adopt the event-mediated approach to quantification.

The structure of the paper is as follows. Section 2 introduces EMT and discusses the advantages which it has been claimed to have over the classical GQT analysis. Section 3 presents relevant facts concerning the behavior of habituals, which have not been considered yet in connection with the theories of quantification and which form the empirical basis of the paper. Subsequently, sections 4 and 5 discuss two approaches to the semantics of habituals and evaluate GQT and EMT with respect to the modeling of the scope of indefinites in habituals in combination with these approaches. First, section 4 shows that neither GQT nor EMT produce the desired results if a quantificational approach to habituality in terms of a generic quantifier is adopted. Section 5 then presents an alternative, non-quantificational approach to habituality and shows that, in combination with it, EMT can successfully account for the semantic behavior of indefinites in habituals, while GQT cannot. Section 6 concludes.

\section{Quantification and events}

In semantic systems that do not take events to be a basic semantic type, quantificational DPs (QPs henceforth) are standardly assumed to denote generalized quantifiers, type $\langle e t, t\rangle$. This implies an asymmetry between subjects and non- 
The semantics of habituality as an argument for event-mediated quantification

subjects: differently from subject QPs, quantificational non-subjects produce a type clash in their base positions. This type clash can be avoided by assuming that non-subject QPs undergo Quantifier Raising (QR; May 1977, 1985) to a position of type $t$, i.e. to $\mathrm{S} / \mathrm{TP}$ (or VP/VoiceP if subjects are generated VP/VoiceP-internally), as schematically shown below. Moreover, Quantifier Raising is also used to model quantifier scope ambiguities, in which case it can also be applied to subjects.
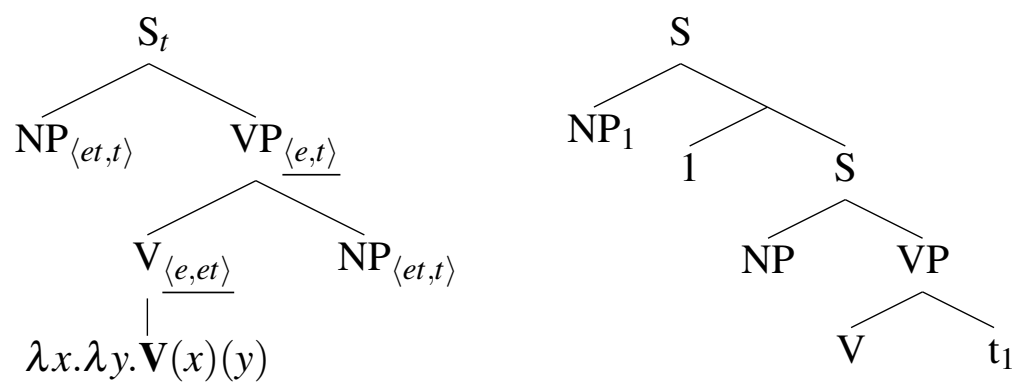

In event semantic frameworks, by contrast, there are more analytical possibilities available as to what quantificational DPs denote and what their semantic type is. To see this, (7) first shows the type composition in the lower verbal domain of a transitive clause, where $v$ is the type of events. ${ }^{1}$

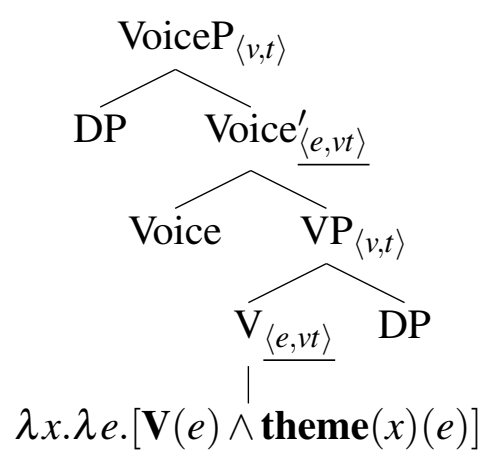

In this configuration, there is no asymmetry anymore between subjects and nonsubjects: the sister constituents of the subject and object DPs in (7) have the same semantic type. Despite this difference from eventless frameworks, the analysis of QPs in terms of generalized quantifiers can be straightforwardly adopted also here, as is done, e.g., in Landman 2000. In this case, being of type $\langle e t, t\rangle$, quantificational subjects and quantificational non-subjects alike must obligatorily undergo QR to a position of type $t$ (i.e. to TP) for type reasons.

However, the type composition in (7) also allows for an alternative treatment of quantificational DPs, namely as expressions of type $\langle\langle e, v t\rangle, v t\rangle$. In this case, QR to

1 Here and below, I do not differentiate between $v \mathrm{P}$ (Chomsky 1995) and VoiceP (Kratzer 1996), whose role is to introduce the external argument in their specifier positions. 
TP is impossible, but QPs can be interpreted in situ or be optionally QRed to VoiceP (position of type $\langle v, t\rangle$ ) for scope reasons. Given this semantic type, the denotation of a QP such as every girl can be as in (9), which is only a small departure from the standard GQT semantics in (8):

$$
\begin{array}{llrl}
\llbracket \text { every } \operatorname{girl} \rrbracket & =\lambda P . \forall x[\operatorname{girl}(x) \rightarrow P(x)] & & \text { GQT } \\
\llbracket \text { every } \operatorname{girl} \rrbracket & =\lambda P . \lambda e \cdot \forall x[\operatorname{girl}(x) \rightarrow P(x)(e)] & & \text { EMT }
\end{array}
$$

Since quantificational DPs of this semantic type are either interpreted in situ or undergo optional QR to a position of type $\langle v, t\rangle$, i.e., a position at which the event argument is not quantified over yet, this implies that quantifiers over individuals introduced by such QPs will always be in the scope of the event quantifier. However, the event quantifier has been observed to take the lowest scope possible with respect to other scope-taking elements such as other quantifiers or negation (Schein 1993; Landman 2000), as the examples below demonstrate. ${ }^{2}$

(10) John kissed every girl.
a. $\forall x \gg \exists e$
b. $* \exists e \gg \forall x$

John didn't kiss Mary.
a. $\neg \gg \exists e$
b. $* \exists e \gg \neg$

This fact, which, following Landman 2000, I will call the Event Type Principle, is straightforwardly accounted for by GQT, insofar as it requires QPs to undergo obligatory QR to a position of type $t$, i.e. above the event quantifier. By contrast, the semantics in (9) fails to account for the Event Type Principle. For this reason, Schein 1993 suggested that the $\langle\langle e, v t\rangle, v t\rangle$-type semantics of QPs should rather be as below, where $\sqsubseteq$ is the part-of relation:

$$
\llbracket \text { every girl } \rrbracket=\lambda P . \lambda e . \forall x\left[\operatorname{girl}(x) \rightarrow \exists e^{\prime}\left[e^{\prime} \sqsubseteq e \wedge P(x)\left(e^{\prime}\right)\right]\right] \quad \mathrm{EMT}^{S}
$$

Instead of containing just one variable ranging over events, the semantics in (12) contains two: one over potentially plural events and one over their parts. The single event variable in standard (neo-)Davidsonian event semantics corresponds here to the variable which ranges over sub-events. This variable is existentially quantified over in the nuclear scope of quantifiers over individuals, and this is precisely what accounts for the Event Type Principle in this framework.

In fact, however, Schein's semantics in (12) is too weak because it suffers from

2 Throughout the paper, ' $\gg$ ' means 'has scope over'. 
The semantics of habituality as an argument for event-mediated quantification

"leakage" (Bayer 1997), i.e. the inability to prevent non- $P$-events from being part of the plural event. Thus, for instance, in (10), the plural event that consists of individual events of kissing of a girl by John should be an event of girl-kissing by John itself, while (12) gives us that it can be any event that contains events of kissing of a girl by John as its sub-events, even if it also contains other kinds of extraneous sub-events. For this reason, Kratzer 2002 suggested that Schein's semantics of QPs should be modified as in (13), where $\sigma$ is the sum operator. This semantics includes a restriction on the plural event which ensures that it is a sum of $P$-events, i.e. that all of its sub-events are of the right kind (for slightly different implementations of this analysis, see also Ferreira 2005; Thomas 2015; Champollion 2016):

$$
\begin{aligned}
\llbracket \text { every girl } \rrbracket= & \lambda P \cdot \lambda e \cdot\left[\forall x\left[\operatorname{girl}(x) \rightarrow \exists e^{\prime}\left[e^{\prime} \sqsubseteq e \wedge P(x)\left(e^{\prime}\right)\right]\right]\right. \\
& \left.\wedge e=\sigma e^{\prime}\left[e^{\prime} \sqsubseteq e \wedge \exists x\left[\operatorname{girl}(x) \wedge P(x)\left(e^{\prime}\right)\right]\right]\right]
\end{aligned}
$$

Kratzer's semantics in (13) gets the scope facts (i.e. the Event Type Principle) right as well, as is shown below for John kissed every girl (tense is ignored).

$$
\begin{array}{lll}
\text { a. } & \text { John kissed every girl. } & \exists e \gg \forall x \gg \exists e^{\prime} \\
\text { b. } & \exists e[\text { agent }(\text { john })(e) & \\
& \wedge \forall x\left[\operatorname{girl}(x) \rightarrow \exists e^{\prime}\left[e^{\prime} \sqsubseteq e \wedge \operatorname{kiss}\left(e^{\prime}\right) \wedge \text { theme }(x)\left(e^{\prime}\right)\right]\right] \\
& \left.\wedge e=\sigma e^{\prime}\left[e^{\prime} \sqsubseteq e \wedge \exists x\left[\operatorname{girl}(x) \wedge \operatorname{kiss}\left(e^{\prime}\right) \wedge \operatorname{theme}(x)\left(e^{\prime}\right)\right]\right]\right]
\end{array}
$$

Thus, both analyses capture the fact that the event quantifier always takes scope under quantifiers over individuals: due to obligatory QR to TP in GQT and due to the presence of an existential quantifier over sub-events in EMT. However, the original motivation for EMT hasn't been to account for the Event Type Principle: GQT can account for it in a much simpler way. The reason why Schein proposed this analysis is that it can also account for some further data which are problematic for classical GQT. One set of such data concerns adverbs/adverbials that can only modify plural events, as illustrated in the examples below from Schein 1993:

a. In slow progression, every organ student struck a note on the Wurlitzer.

b. Unharmoniously, every organ student sustained a note on the Wurlitzer for sixteen measures.

Each of the individual events of striking/sustaining of a note by an organ student cannot occur in slow progression, nor can it be harmonious or unharmonious; modifiers such as in slow progression and unharmoniously can apply to sequences of events (i.e. plural events), but not to singular events. Now, the logical forms of the sentences above that employ the semantics for every organ student along the lines of (12) or (13) contain a variable ranging over sum events, so adverbials like in slow 
progression and unharmoniously can modify the sum event containing sub-events of individual organ students striking/sustaining a note. By contrast, no such variable is available in the representations provided by standard (neo-)Davidsonian event semantics, and hence in slow progression and unharmoniously can only apply to the individual striking/sustaining events.

Another argument in favor of EMT comes from mixed cumulative/distributive readings, which Schein (1993) illustrates with examples like the following one:

$$
\frac{\text { Three video games taught every quarterback two new plays. }}{\underbrace{}_{\text {distributive }}}
$$

This sentence has a reading according to which three video games is interpreted cumulatively, whereas every quarterback is interpreted distributively with two new plays in its scope: three video games (between them) taught every quarterback two (other) new plays. Neo-Davidsonian event semantics, which separates the external argument as a distinct theta-role predicate, combined with the semantics for QPs along the lines of (12)/(13), which introduces two event variables, can account for this interpretation, as the logical form below from Ferreira 2005: 25 demonstrates (again, tense is ignored):

$$
\begin{aligned}
& \exists e \exists X[\operatorname{videogame}(X) \wedge|X|=3 \wedge \operatorname{agent}(X)(e) \\
& \wedge \forall y\left[\text { quarterback } ( y ) \rightarrow \exists e ^ { \prime } \left[e^{\prime} \sqsubseteq e \wedge \operatorname{to}(y) \underline{\left(e^{\prime}\right)} \wedge \exists Z[\operatorname{newplay}(Z) \wedge|Z|=2\right.\right. \\
& \left.\left.\left.\wedge \operatorname{theme}(Z)\left(e^{\prime}\right) \wedge \operatorname{teach}\left(e^{\prime}\right)\right]\right]\right] \\
& \wedge \forall e^{\prime}\left[e ^ { \prime } \sqsubset e \rightarrow \exists y \left[\operatorname{quarterback}(y) \wedge \operatorname{to}(y) \underline{\left(e^{\prime}\right)} \wedge \exists Z[\operatorname{newplay}(Z) \wedge|Z|=2\right.\right. \\
& \wedge \operatorname{theme}(Z) \underline{\left.\left.\left.\left.\left(e^{\prime}\right) \wedge \operatorname{teach}\left(e^{\prime}\right)\right]\right]\right]\right]}
\end{aligned}
$$

Video games act here as the agent of the sum event, whereas both quarterbacks and new plays are participants in its sub-events, and this is what allows to capture the mixed cumulative/distributive pattern. By contrast, this is not possible in an event semantic framework which does not separate the agent theta-role and does not introduce a variable ranging over sum events. ${ }^{3}$

The goal of this paper is to show that, in fact, EMT also provides a better account of the Event Type Principle than GQT if a broader range of data is considered. More specifically, in addition to cases involving a universal quantifier over individuals and an existential event quantifier, we will also examine inverse cases with an existential quantifier over individuals and a generic or universal event quantifier. Hence, the next section presents data concerning the interpretation of indefinites in bare habituals and in sentences that contain overt adverbs of quantification.

3 See Champollion 2010, who shows that such mixed cumulative/distributive readings can also be accounted for in eventless frameworks. 
The semantics of habituality as an argument for event-mediated quantification

\section{Habituals: bare and quantified}

\subsection{Interpretation of indefinites}

This section introduces the first crucial piece of data, which concerns the semantic behavior of indefinites in bare habituals and in sentences that contain overt adverbs of quantification or other quantificational elements introducing pluralities (I will refer to the latter type of sentences as quantified habituals, for reasons that become clear in section 3.2). More specifically, this piece of data has to do with the availability of narrow scope readings of indefinites in these contexts.

The semantics of bare habitual sentences, such as the ones in (18) below, is usually assumed to contain a silent generic quantifier GEN (see, e.g., Krifka, Pelletier, Carlson, ter Meulen, Link \& Chierchia 1995), an unpronounced generic counterpart of overt adverbs of quantification (Q-adverbs) like always or often.

$$
\begin{aligned}
& \text { a. John smokes. } \\
& \text { b. John smokes a pipe. } \\
& \text { c. John smokes cigarettes. }
\end{aligned}
$$

Quantificational adverbs like always as well as quantificational adverbials like every morning introduce quantifiers over events or times ${ }^{4}$, which enter into scope relations with other quantifiers, as the sentences below with the singular indefinite a cigarette demonstrate. Hence, both scope configurations are available in these examples, even though only one of them is pragmatically felicitous: the wide scope reading of a cigarette suggests that the same cigarette is repeatedly smoked over a long period of time, which is in conflict with world knowledge (notice that, by contrast, a pipe or the plural indefinite cigarettes are pragmatically fine).

John smokes a cigarette every morning.

John always smokes a cigarette.
a. $\# \exists \gg \forall$
b. $\forall \gg \exists$

If GEN is indeed a quantifier like the one introduced by always or every morning, one would expect bare habituals containing indefinites to display analogous scope ambiguities. However, this does not seem to be the case, as examples like (20) suggest: while the wide scope reading of a cigarette is pragmatically infelicitous like before (notice that the bare habitual with a pipe in (18) is fine), the fact that (20) is odd altogether suggests that the narrow scope reading of a cigarette is not available

4 In later sections, I will argue that Q-adverb(ial)s like always and every morning introduce quantification over times. For now I am staying neutral in this respect however, given that it is commonly assumed that Q-adverbs quantify over events. 
for some reason, as has been repeatedly pointed out in the literature (possibly the earliest mentioning of this fact can be found in Carlson 1977). ${ }^{5}$

\#John smokes a cigarette.
a. $\# \exists \gg$ GEN
b. $* \mathrm{GEN} \gg \exists$

Note that, under the assumption that (20) contains the generic quantifier GEN, the scope facts in (20) seem to be just another manifestation of the Event Type Principle discussed above: the event quantifier (in this case, GEN) takes the lowest scope possible with respect to quantifiers over individuals. In the literature on genericity and habituality, the obligatory wide scope of indefinites in bare habituals has often been accounted for by assuming that there is something special about GEN as compared to overt Q-adverbs. One possibility, explored in Cohen 2013, is to assume that the null generic quantifier differs from overt adverbs of quantification insofar as it is introduced by type-shifting, whence its narrow scope. More commonly, however, a more radical departure from the analysis of bare habituals in terms of GEN is entertained, whereby they are assumed to contain a scopeless non-quantificational generic operator, rather than the generic quantifier GEN (for various versions of this analysis, see Carlson 1977; Rimell 2004; van Geenhoven 2004; Ferreira 2005; Kratzer 2008; Boneh \& Doron 2013). Sections 4 and 5 will discuss both the quantificational and the non-quantificational treatment of bare habituals in more detail. Before we get there, however, another important piece of data concerning bare habituals needs to be introduced.

\subsection{Q-adverbs in habituals}

Another crucial piece of data concerning habituals has to do with the fact that, in languages which have specialized habitual tense forms, these tense forms can combine with adverbs of quantification. This can be seen even in English, which

5 Note that sentences like (20) are fine in the presence of overt or implicit (contextually specified) restrictors, as the examples below demonstrate:

$$
\text { John smokes a cigarette }\left\{\begin{array}{c}
\text { when he is nervous } \\
\text { after dinner }
\end{array}\right\} \text {. }
$$

$$
\begin{aligned}
& \text { A: What does John do before going to sleep? } \\
& \text { B: He smokes a cigarette. }
\end{aligned}
$$

I won't be concerned with such cases in this paper, simply assuming that they contain a silent always as a default adverb of quantification (Lewis 1975), which is licensed if an overt or implicit restrictor is present. In this way, the examples above are just a sub-case of the paradigm in (19). 
The semantics of habituality as an argument for event-mediated quantification

does not have rich aspectual morphology, in the case of simple present habituals and, more clearly, the used to construction, as the examples below show:
a. John used to smoke.
b. *John used to smoke once/yesterday.
c. John used to smoke every day.
d. John used to always smoke (on the phone).

The incompatibility of the used to form with adverbs like once and yesterday shows that it is a specialized habitual form, which cannot occur in episodic environments. On the other hand, it is perfectly compatible with adverbs of quantification, such as always and every day. The same is of course also true of the simple present form, which occurs not only in bare habituals, but also in sentences containing adverbs of quantification. It is for this reason that I will call such sentences quantified habituals.

This fact holds in a more transparent way for languages with richer aspectual morphology that have specialized habitual marking, such as, e.g., Hindi/Urdu and Ewe, cf. the examples below. In particular, the specialized habitual morpheme -taa in Hindi/Urdu can co-occur with quantificational adverbials like every day; in fact, the habitual aspect must be used when such adverbials are present. The same holds for the habitual marker -na in Ewe.

$$
\text { Raam (roz / / ek baar } / * \text { kal) sigret pii-taa thaa. }
$$
R. every_day one time yesterday cigarette drink-HAB be.PAST 'Ram smoked/would smoke (every day/*once/*yesterday).' (Hindi/Urdu) ${ }^{6}$ Agbenyo yi-na suku ydi sia ydi.

A. go-HAB school morning that morning

'Agbenyo goes to school every morning.'

The fact that the habitual verbal morphology is not only compatible with adverbs of quantification, but is even required in their presence, is often not taken into consideration in the analyses of the semantics of habituality. However, this fact is crucial for understanding habitual semantics, given that the habitual morphology should be attempted to be given a unified analysis across its uses in bare and quantified habituals. In particular, the problem is that it is not immediately clear how to avoid double event plurality without assuming semantic inertness of habitual markers in the presence of Q-adverbs. The next section will show that this is a serious problem for a quantificational analysis of habituals.

6 Gurmeet Kaur, p.c.

7 Agbojo \& Litvinov 1997. 
Alexeyenko

\section{Quantificational analysis of habituals}

\subsection{GQT}

This section discusses the quantificational analysis of habituals and shows that, in combination with GQT, it fails to adequately model the semantic behavior of indefinites in bare and quantified habituals in a unified way.

Let us first spell out the quantificational analysis of habituals based on the silent generic quantifier GEN in more precise terms. GEN is usually assumed to be a modalized quantifier with quasi-universal force, which is designed to account for such properties of generics as, e.g., their non-accidental law-like nature and their tolerance to exceptions (cf. Dahl 1975; Chierchia 1995; Krifka et al. 1995; Cohen 1999; Greenberg 2003). Furthermore, given that the habitual is a variety of the imperfective aspect, it is plausible to assume that its semantics is introduced by a special aspectual head. On the quantificational analysis of habituals, the denotation of this habitual Asp head, which is null in English, may be formalized for example along the following lines:

$$
\llbracket \mathrm{HAB} \rrbracket=\lambda P . \lambda t . \exists e\left[t \subseteq \tau(e) \wedge \mathrm{GEN} e^{\prime}\left[e^{\prime} \sqsubseteq e \wedge \mathbf{C}\left(e^{\prime}\right)\right]\left[P\left(e^{\prime}\right)\right]\right]
$$

Like any imperfective head, HAB takes a property of events, quantifies over the event variable, maps the event to its run time by means of the temporal trace function $\tau$ (cf. Krifka 1989), and relates the event time to some reference time $t$, such that the reference time is included in the event time (cf. Reichenbach 1947; Klein 1994; Giorgi \& Pianesi 1997; Kratzer 1998). What is special about HAB in (24) as compared to other imperfective heads is that the event quantifier is generic rather than existential and that the reference time is located within the run time of the entire habitual sequence rather than any of its sub-events. ${ }^{8}$

Now, given the denotation of HAB in (24), GQT unproblematically accounts for the obligatory wide scope of indefinites in bare habituals and, thus, for the pragmatic infelicity of sentences like John smokes a cigarette: because of the obligatory QR of QPs above the event quantifier, the only scope configuration it can derive for such sentences is $\exists x \gg$ GENe. What is more, this scope configuration gets derived without any further assumptions (such as, e.g., type-shifting in Cohen 2013), since QPs must undergo QR above the generic quantifier, while the aspectual head HAB, which introduces the generic quantifier, cannot be QRed.

However, GQT encounters a problem with quantified habituals under the assumption that also such sentences contain $\mathrm{HAB}$, as the data discussed in the previous

8 The semantics of HAB does not necessarily need to be formalized in such a way that it contains a variable over sum events, i.e., the entire habitual sequences, like in (24). Alternatively, it can also be defined by means of convex closures (cf., e.g., Boneh \& Doron 2008). 
The semantics of habituality as an argument for event-mediated quantification

section suggest. Thus, for instance, John smokes a cigarette every morning would have the following two scope possibilities if GQT is adopted in combination with the semantics of HAB in (24):

(25) John smokes a cigarette every morning.
a. $\forall \gg \exists \gg$ GEN
b. $\quad \exists \gg \forall \gg$ GEN

In both cases, there is too much event plurality: both of the readings imply that a habitual series of smoking events occurs per morning, yielding an unusual short-lived habituality. Moreover, in both cases the indefinite takes scope over the generic quantifier, which should result in pragmatic infelicity, contrary to fact.

Note, finally, that this problem of double event plurality is not restricted to cases with adverbs of quantification, but also occurs when other, non-temporal quantifiers are present, as, e.g., in the example below. Again, the readings that this sentence is predicted to have imply that John habitually smokes in each of the pubs.

John smokes a cigarette in every pub he walks into.

Intuitively, the situation could be saved if the event quantifier was existential in such cases, i.e. if the aspectual head contributed an episodic semantics. This would mean, however, that the habitual morphology will have to have a different semantics in sentences containing adverbs of quantification and other quantifiers introducing pluralities than its semantics in bare habituals, and thus a unified analysis of habituality would not be possible.

\subsection{EMT}

The quantificational approach to habituals faces the problem of double event plurality in combination with EMT in the same way as it does in combination with GQT. In addition, however, it also fails to account for the semantic scope of indefinites in bare habituals-something that GQT has no problems with, as we have seen in the previous section. In particular, given the semantic type of QPs under EMT $(\langle\langle e, v t\rangle, v t\rangle)$, they can only be QRed to positions below the event quantifier, if they undergo QR at all. Yet this implies that bare habitual sentences like John smokes a cigarette will always get the scope configuration GENe $\gg \exists x$, and so should be pragmatically fine, contrary to fact. What is more, it is not clear how to derive the wide scope readings of indefinites in bare habituals at all.

The scope configuration that we would want for bare habitual sentences under EMT is rather $\exists e \gg \exists x \gg \mathrm{GEN} e^{\prime}$, where existential quantification over sum events is contributed by the aspectual head, whereas generic quantification over sub-events 
is introduced in the nuclear scope of quantifiers over individuals, as proposed by Schein (1993). However, this would mean that quantificational determiners every, $a$, and so on, will have to be assumed to be ambiguous between two meanings that differ only with respect to the event quantifier that these determiners host in their nuclear scope, namely one with an existential and one with a generic quantifier. In addition, it would also be unclear how to motivate the fact that habitual morphology contributes existential quantification over events.

Thus, independently of the choice of the analysis of QPs, the analysis of habituality in terms of the generic quantifier does not seem to allow for a unified account of the semantic behavior of indefinites in bare habituals and in habituals containing overt quantification. The next section will consider an alternative, non-quantificational approach to habituality.

\section{Non-quantificational analysis of habituals}

\subsection{Habituals as event pluralities}

The semantics of habituals has a common alternative analysis to the one in terms of the generic quantifier GEN. According to it, a habitual series should be modeled as an event plurality, rather than as quantification over events. In what follows, I will outline the core idea of this analysis and propose a possible formalization; for other implementations of this idea see Carlson 1977; Rimell 2004; van Geenhoven 2004; Ferreira 2005; Kratzer 2008; Deo 2009; Boneh \& Doron 2013; Altshuler 2014; Thomas 2015.

The main insight of the analysis of habituals in terms of event pluralities comes from the comparison between habituals and progressives, rather than the comparison between (bare) habituals and sentences containing Q-adverbs, which has been crucial for the development of the quantificational analysis of habituals. In particular, it relates to the well-established view in the typological and theoretical literature on aspect that the habitual and the progressive form a natural class, being two varieties of the imperfective (cf., e.g., Comrie 1976). This implies that they must have a shared semantic core, which should be adequately captured in the semantics.

More specifically, the idea is that also habituals can be modeled by means of an inertia-world semantics, which has been developed for progressives (Dowty 1979; Landman 1992; Portner 1998). According to this semantics, a progressive is true iff there is a 'stage' event in the actual world that develops into a complete VP-event in all the worlds in the circumstantial modal base that rank best with respect to the non-interruption ordering source. The same can also be said of habituals, with the only difference that their 'continuation' events in the relevant possible worlds are plural, while the continuation events of progressives are singular. In other words, a 
The semantics of habituality as an argument for event-mediated quantification

habitual is true iff there is a singular or plural $P$-event in the actual world such that it is a non-final part of a plural $P$-event in all the worlds in which nothing irrelevant accidentally interrupts it and prevents from continuing. Thus, the denotation of the non-quantificational version of the aspectual head HAB may now be formalized in the following way:

$$
\begin{aligned}
\llbracket \mathrm{HAB} \rrbracket= & \lambda P . \lambda t . \exists e[t \subseteq \tau(e) \wedge P(e)(w) \\
& \wedge \forall w^{\prime}\left[w^{\prime} \in \operatorname{BEST}(\operatorname{CIRC}(e)(w))(\operatorname{NINT}(e)(w))\right. \\
& \left.\left.\rightarrow \exists \varepsilon\left[\tau(e) \subset \mathrm{nf} \tau(\varepsilon) \wedge \neg \operatorname{ATOM}(\varepsilon)\left(w^{\prime}\right) \wedge P(\varepsilon)\left(w^{\prime}\right)\right]\right]\right]
\end{aligned}
$$

Several building blocks of the formula in (27) need to be defined, which is done below. These include the set of the best-ranked worlds in the circumstantial modal base with respect to the non-interruption ordering source, the non-final-interval relation $\subset_{\text {nf }}$, and atomicity.

$$
\begin{aligned}
& \operatorname{BEst}(\operatorname{CiRc}(e)(w))(\operatorname{Nint}(e)(w)):= \\
& \left\{w^{\prime} \in \bigcap \operatorname{CiRc}(e)(w): \neg \exists w^{\prime \prime} \in \bigcap \operatorname{CiRC}(e)(w)\left[w^{\prime \prime} \neq w^{\prime} \wedge w^{\prime \prime} \leqslant \operatorname{Nint}(e)(w) w^{\prime}\right]\right\} \\
& \begin{aligned}
i^{\prime} \subset \mathrm{nf} i^{\prime \prime}:= & \forall t^{\prime} \forall t^{\prime \prime}\left[\left(t^{\prime} \subseteq i^{\prime} \wedge t^{\prime \prime} \subseteq i^{\prime \prime}\right)\right. \\
& \left.\rightarrow \exists t_{u}^{\prime} \exists t_{u}^{\prime \prime}\left[\left(t_{u}^{\prime} \succ t^{\prime} \vee t_{u}^{\prime}=t^{\prime}\right) \wedge\left(t_{u}^{\prime \prime} \succ t^{\prime \prime} \vee t_{u}^{\prime \prime}=t^{\prime \prime}\right) \wedge\left(t_{u}^{\prime \prime} \succ t_{u}^{\prime}\right)\right]\right]
\end{aligned} \\
& \operatorname{ATOM}(e):=\forall e^{\prime}\left[e^{\prime} \sqsubseteq e \rightarrow e^{\prime}=e\right]
\end{aligned}
$$

According to (27), the crucial property of habituals, which distinguishes them from progressives, is the non-atomicity requirement with respect to the $P$-event in the relevant inertia worlds (which may or may not include the actual world). Thus, while specialized habitual markers contain the non-atomicity requirement in their semantics, the semantics of specialized progressive markers contains the atomicity requirement, and imperfective markers that are ambiguous between the progressive and the habitual are underspecified with respect to (non-)atomicity. In the case of habituals, it is this non-atomicity requirement that implies plurality of events that form a habitual series, taking over this role from generic quantification over events in a quantificational approach to habituals.

For reasons of readability, the modal-temporal semantics of habituality in (27) will in what follows be abbreviated to the shorthand HBTL. Thus, the denotation of HAB that will be used in the next sections is as defined in (31) below:

$$
\llbracket \mathrm{HAB} \rrbracket=\lambda P . \lambda t . \exists e[t \subseteq \tau(e) \wedge \operatorname{HBTL}(e) \wedge P(e)]
$$

Equipped with this semantics of HAB, we can now see if the two approaches to QPs in combination with this non-quantificational analysis of habituality are able to account for the semantic behavior of indefinites in bare and quantified habituals in a unified way. 


\subsection{Bare habituals}

Let us start with bare habituals, using again John smokes a cigarette as a test example. Before spelling out its semantics under GQT and EMT, (32) first illustrates my assumptions with respect to the basic syntactic architecture of a transitive clause and the corresponding type composition (cf., e.g., Giorgi \& Pianesi 1997; Kratzer 1998; Alexiadou, Rathert \& von Stechow 2003). Here, $i$ is the type of times, or, more precisely, time intervals.

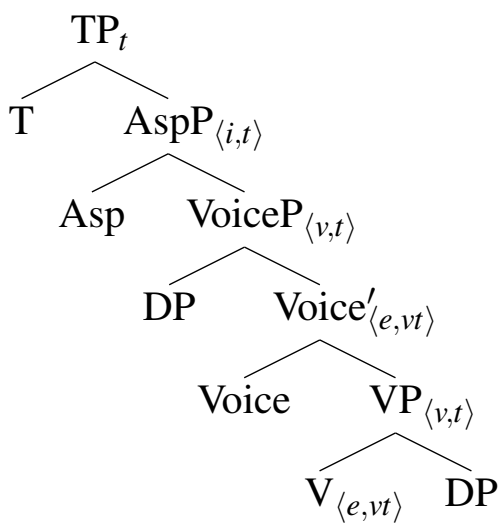

It has already been mentioned before that the aspectual head Asp relates the event time to the reference time. By contrast, the function of the tense head $\mathrm{T}$ is to relate the reference time and the utterance time. Accordingly, the locus of event time adverbials (such as, e.g., on Monday, but also every morning and always) is $\mathrm{VP} /$ VoiceP, the locus of reference time adverbials (e.g. by tomorrow or until July) is AspP, whereas the locus of utterance time adverbials (e.g. now) is TP.

Now, given the syntax in (32), the LF of John smokes a cigarette under GQT will be as in (33), with a cigarette undergoing obligatory QR to TP for type reasons. (34) provides the interpretation we get for this LF using the non-quantificational denotation of HAB in (31) and assuming that PRES in matrix clauses denotes the deictic pronoun now that refers to the time of utterance (cf. von Stechow 2009). ${ }^{9}$

$$
\begin{aligned}
& \left.\left.\left[\mathrm{TP}[\text { a cigarette }]_{1} \lambda_{1}\left[\mathrm{TP} \text { PRES [AspP HAB [VoiceP John smoke } \mathrm{t}_{1}\right]\right]\right]\right] \\
& \exists x[\text { cigarette }(x) \wedge \exists e[\text { now } \subseteq \tau(e) \wedge \operatorname{HBTL}(e) \wedge \operatorname{smoke}(x)(\text { john })(e)]]
\end{aligned}
$$

This semantics adequately represents the pragmatically infelicitous reading that John smokes a cigarette has: it states that the same cigarette is smoked in the entire habitual series. Moreover, no other scope possibility is available for this sentence

9 To make the semantic formulae below more readable, I will represent the meanings of verbs with $n$ syntactic arguments as $n$-ary relations, instead of representing their arguments as separate $\theta$-role conjuncts. 
The semantics of habituality as an argument for event-mediated quantification

under this analysis, as desired.

In fact, the situation is not much different under EMT, as (35) and (36) below show: even though a cigarette can now be interpreted in situ (or be QRed to VoiceP, which would be truth-conditionally equivalent), nothing changes in its 'wide' scope relation with respect to the habitual operator, and therefore the pragmatically odd reading obtains as the only possibility. ${ }^{10}$

$$
\begin{aligned}
& {[\mathrm{TP} \text { PRES [AspP HAB [VoiceP John smoke a cigarette]]] }} \\
& \exists e[\text { now } \subseteq \tau(e) \wedge \operatorname{HBTL}(e) \wedge \exists x[\operatorname{cigarette}(x) \wedge \operatorname{smoke}(x)(\text { john })(e)]]
\end{aligned}
$$

Thus, in combination with a non-quantificational approach to habituality, both analyses of QPs can successfully account for the obligatory wide scope of indefinites in bare habituals.

\subsection{Quantified habituals}

Let us now turn to quantified habituals containing adverbs of quantification, such as John smokes a cigarette every morning. As already mentioned above, I assume that phrases like every morning are (quantificational) event time adverbials, and thus are VP/VoiceP-adjuncts. Furthermore, I also assume that they are PPs, whose null P head relates the time they introduce to the run time of the event, as shown below. Q-adverbs like sometimes, often, and always are treated in the same way, because I assume that they spell-out what is underlyingly [PP at some/often/all times].

$$
\begin{aligned}
& {[\mathrm{PP} \emptyset / \mathrm{on}[\mathrm{DP} \text { every morning]] }} \\
& \llbracket \emptyset / \mathrm{on} \rrbracket=\lambda t . \lambda P . \lambda e .[P(e) \wedge \tau(e) \subseteq t]
\end{aligned}
$$

Now, under GQT, both a cigarette and every morning denote generalized quantifiers (the latter over times: $\lambda P . \forall t[$ morning $(t) \rightarrow P(t)]$ ) and thus have to undergo QR to TP. If every morning scopes above a cigarette, the interpretation of our test sentence under this analysis is as shown below.

(39) $\quad[\text { те [every morning }]_{2} \lambda_{2}$ [те [a cigarette $]_{1} \lambda_{1}$ [те PRES [AspP HAB [VoiceP John smoke $\left.\left.\left.\left.\left.t_{1}\left[\mathrm{PP}_{2}\right]\right]\right]\right]\right]\right]$

$$
\begin{aligned}
& \forall t[\operatorname{morning}(t) \rightarrow \exists x[\text { cigarette }(x) \wedge \exists e[\text { now } \subseteq \tau(e) \wedge \operatorname{HBTL}(e) \\
& \wedge \text { smoke }(x)(\text { john })(e) \wedge \tau(e) \subseteq t]]]
\end{aligned}
$$

This semantics is problematic for a number of reasons. First, it states that there is a habitual series of smoking events per morning, which is not the most natural

10 Indefinites do not introduce existential quantification over events in the scope of their existential quantifier (Schein 1993). Thus, the denotation of a cigarette is $\lambda P . \lambda e . \exists x[$ cigarette $(x) \wedge P(x)(e)]$. 
interpretation of John smokes a cigarette every morning, if this sentence has that reading at all. Moreover, the same cigarette is smoked in all sub-events of each of such habitual series, which should trigger pragmatic infelicity, contrary to fact. And finally, the run time of each of these habitual series is included in the time of the respective morning, but at the same time, the run times of all of them include now (i.e., these are ongoing events), which is difficult to make sense of. Note that the inverse scope possibility (with a cigarette scoping above every morning) is available as well, but does not make things better.

Let us now see what happens under EMT. The denotation of every morning is in this case as below (cf. (13)):

$$
\begin{aligned}
\llbracket \text { every morning } \rrbracket= & \lambda P \cdot \lambda e \cdot\left[\forall t\left[\operatorname{morning}(t) \rightarrow \exists e^{\prime}\left[e^{\prime} \sqsubseteq e \wedge P(t)\left(e^{\prime}\right)\right]\right]\right. \\
& \left.\wedge e=\sigma e^{\prime}\left[e^{\prime} \sqsubseteq e \wedge \exists t\left[\operatorname{morning}(t) \wedge P(t)\left(e^{\prime}\right)\right]\right]\right]
\end{aligned}
$$

If a cigarette is interpreted in situ and every morning undergoes QR to VoiceP, John smokes a cigarette every morning gets the following interpretation:

[TP PRES [AspP HAB [VoiceP [every morning] ${ }_{1} \lambda_{1}$ [VoiceP John smoke a cigarette $\left.\left.\left.\left.\left[\mathrm{PP}_{1}\right]\right]\right]\right]\right]$

$$
\begin{aligned}
& \exists e\left[\text { now } \subseteq \tau ( e ) \wedge \operatorname { H B T L } ( e ) \wedge \forall t \left[\operatorname { m o r n i n g } ( t ) \rightarrow \exists e ^ { \prime } \left[e^{\prime} \sqsubseteq e\right.\right.\right. \\
& \left.\left.\wedge \exists x\left[\operatorname{cigarette}(x) \wedge \operatorname{smoke}(x)(\mathbf{j o h n})\left(e^{\prime}\right)\right] \wedge \tau\left(e^{\prime}\right) \subseteq t\right]\right] \wedge e=\sigma e^{\prime}\left[e^{\prime} \sqsubseteq e\right. \\
& \left.\left.\wedge \exists t\left[\operatorname{morning}(t) \wedge \exists x\left[\operatorname{cigarette}(x) \wedge \operatorname{smoke}(x)(\mathbf{j o h n})\left(e^{\prime}\right)\right] \wedge \tau\left(e^{\prime}\right) \subseteq t\right]\right]\right]
\end{aligned}
$$

The semantics above adequately captures the most natural reading of our test sentence. It says that there is an ongoing habitual series of smoking events whose sub-events distribute over mornings and that there is a potentially different cigarette that is smoked in each of the morning smoking events. This is the pragmatically fine narrow scope reading of a cigarette; the pragmatically infelicitous wide scope reading can be captured as well-as desired-if a cigarette is QRed above every morning.

This shows that GQT and EMT are not on a par with respect to their ability to provide an adequate semantics for quantified habitual sentences: only EMT is able to account for it, and only in combination with a non-quantificational treatment of habituality in terms of event plurality.

\section{Conclusion}

The goal of this paper has been two-fold. On the one hand, it has had as its aim an analysis of the semantics of habituality in the framework of event semantics. In this respect, it has been argued that a proper treatment of habituality must allow (a) a unified analysis of the habitual and the progressive as two different types of the 
The semantics of habituality as an argument for event-mediated quantification

imperfective and (b) a unified analysis of bare habituals and quantified habituals, i.e. habituals that contain adverbs of quantification or other, non-temporal kinds of quantificational elements introducing pluralities. The paper has shown that these desiderata can only be met by a non-quantificational analysis that treats habituality in terms of event plurality rather than event quantification.

On the other hand, the paper has also aimed to evaluate two approaches to quantification, GQT and EMT, with respect to their compatibility with event semantics by using habituals as a testing ground. It has been shown that GQT and EMT are not equally suitable for event semantics, as only the latter can successfully account for the scopal behavior of indefinites in bare and quantified habituals in a unified way, i.e. for their obligatory wide scope in bare habituals (which looks reminiscent of the Event Type Principle in the episodic domain) and their scopal flexibility in quantified habituals. Thus, these facts concerning the scope of the event quantifier in habituals provide a further argument in favor of modeling quantification with the mediation of events, in addition to the existing arguments from adverbials that can modify only plural events and from mixed cumulative/distributive readings. In fact, habituals point out a problem that is very similar in its nature to the one raised by modifiers of plural events: the inability of classical GQT integrated into standard event semantics to sandwich a distributive quantifier between two event quantifiers, for the simple reason that it does not have two event quantifiers at its disposal. The presence of this 'split scope' of event quantifiers is detectable in episodic contexts only when the higher sum event is forced to be plural by appropriate modifiers, and the same can be done in non-episodic contexts by means of habituals.

\section{References}

Agbojo, Kofi \& Vladimir Litvinov. 1997. The expression of action plurality in Ewe. In Viktor Xrakovskij (ed.), Typology of Iterative Constructions, 189-202. Munich and Newcastle: Lincom Europa.

Alexiadou, Artemis, Monika Rathert \& Arnim von Stechow (eds.). 2003. Perfect Explorations. Berlin: Mouton de Gruyter.

Altshuler, Daniel. 2014. A typology of partitive aspectual operators. Natural Language and Linguistic Theory 32(3). 735-775. doi:10.1007/s11049-0149232-1.

Barwise, Jon \& Robin Cooper. 1981. Generalized quantifiers and natural language. Linguistics and Philosophy 4(2). 159-219. doi:10.1007/BF00350139.

Bayer, Samuel L. 1997. Confessions of a Lapsed Neo-Davidsonian: Events and Arguments in Compositional Semantics. New York: Garland.

Boneh, Nora \& Edit Doron. 2008. Habituality and the habitual aspect. In Susan D. 
Rothstein (ed.), Theoretical and Crosslinguistic Approaches to the Semantics of Aspect, 321-347. Amsterdam: John Benjamins.

Boneh, Nora \& Edit Doron. 2013. Hab and Gen in the expression of habituality. In Alda Mari, Claire Beyssade \& Fabio Del Prete (eds.), Genericity, 176-191. Oxford: Oxford University Press.

Carlson, Gregory N. 1977. Reference to Kinds in English. Amherst, MA: University of Massachusetts dissertation.

Champollion, Lucas. 2010. Cumulative readings of every do not provide evidence for events and thematic roles. In Maria Aloni, Harald Bastiaanse, Tikitu de Jager \& Katrin Schulz (eds.), Logic, Language and Meaning: 17th Amsterdam Colloquium, 213-222. Berlin: Springer. doi:https://doi.org/10.1007/978-3-64214287-1_22.

Champollion, Lucas. 2016. Overt distributivity in algebraic event semantics. Semantics and Pragmatics 9(16). 1-65. doi:http://dx.doi.org/10.3765/sp.9.16.

Chierchia, Gennaro. 1995. Individual-level predicates as inherent generics. In Gregory N. Carlson \& Francis Jeffry Pelletier (eds.), The Generic Book, 176223. Chicago, IL: University of Chicago Press.

Chomsky, Noam. 1995. The Minimalist Program. Cambridge, MA: MIT Press.

Cohen, Ariel. 1999. Think Generic! The Meaning and Use of Generic Sentences. Stanford, CA: CSLI Publications.

Cohen, Ariel. 2013. No quantification without reinterpretation. In Alda Mari, Claire Beyssade \& Fabio Del Prete (eds.), Genericity, 334-351. Oxford: Oxford University Press.

Comrie, Bernard. 1976. Aspect: An Introduction to the Study of Verbal Aspect and Related Problems. Cambridge: Cambridge University Press.

Dahl, Östen. 1975. On generics. In Edward L. Keenan (ed.), Formal Semantics of Natural Language, 99-111. Cambridge: Cambridge University Press.

Deo, Ashwini. 2009. Unifying the imperfective and the progressive: partitions as quantificational domains. Linguistics and Philosophy 32(5). 475-521. doi:https://doi.org/10.1007/s10988-010-9068-z.

Dowty, David R. 1979. Word Meaning and Montague Grammar: The Semantics of Verbs and Times in Generative Semantics and in Montague's PTQ. Dordrecht: Reidel.

Ferreira, Marcelo. 2005. Event Quantification and Plurality. Cambridge, MA: Massachusetts Institute of Technology dissertation.

van Geenhoven, Veerle. 2004. For-adverbials, frequentative aspect, and pluractionality. Natural Language Semantics 12(2). 135-190. doi:https://doi.org/10.1023/B:NALS.0000031389.36427.af.

Giorgi, Alessandra \& Fabio Pianesi. 1997. Tense and Aspect: From Semantics to Morphosyntax. Oxford: Oxford University Press. 
The semantics of habituality as an argument for event-mediated quantification

Greenberg, Yael. 2003. Manifestations of Genericity. New York: Routledge.

Keenan, Edward L. \& Jonathan Stavi. 1986. A semantic characterization of natural language determiners. Linguistics and Philosophy 9(3). 253-326. doi:https://doi.org/10.1007/BF00630273.

Klein, Wolfgang. 1994. Time in Language. London and New York: Routledge.

Kratzer, Angelika. 1996. Severing the external argument from its verb. In Johan Rooryck \& Laurie Zaring (eds.), Phrase Structure and the Lexicon, 109-137. Dordrecht: Kluwer.

Kratzer, Angelika. 1998. More structural analogies between pronouns and tenses. In Devon Strolovitch \& Aaron Lawson (eds.), Semantics and Linguistic Theory (SALT) 8, 92-110. Ithaca, NY: CLC Publications, Cornell University. doi:http://dx.doi.org/10.3765/salt.v8i0.2808.

Kratzer, Angelika. 2002. The event argument and the semantics of verbs. Unpublished manuscript, University of Massachusetts at Amherst. https://works. bepress.com/angelika_kratzer/5/.

Kratzer, Angelika. 2008. On the plurality of verbs. In Johannes Dölling, Tatjana Heyde-Zybatow \& Martin Schäfer (eds.), Event Structures in Linguistic Form and Interpretation, 269-300. Berlin: Walter de Gruyter.

Krifka, Manfred. 1989. Nominal reference, temporal constitution and quantification in event semantics. In Renate Bartsch, Johan van Benthem \& Peter van Emde Boas (eds.), Semantics and Contextual Expression, 75-115. Dordrecht: Foris.

Krifka, Manfred, Francis Jeffry Pelletier, Gregory N. Carlson, Alice ter Meulen, Godehard Link \& Gennaro Chierchia. 1995. Genericity: An introduction. In Gregory N. Carlson \& Francis Jeffry Pelletier (eds.), The Generic Book, 1-124. Chicago, IL: University of Chicago Press.

Landman, Fred. 1992. The progressive. Natural Language Semantics 1(1). 1-32. doi:https://doi.org/10.1007/BF02342615.

Landman, Fred. 2000. Events and Plurality: The Jerusalem Lectures. Dordrecht: Kluwer.

Lewis, David. 1975. Adverbs of quantification. In Edward L. Keenan (ed.), Formal Semantics of Natural Language, 3-15. Cambridge: Cambridge University Press.

May, Robert. 1977. The Grammar of Quantification. Cambridge, MA: Massachusetts Institute of Technology dissertation.

May, Robert. 1985. Logical Form: Its Structure and Derivation. Cambridge, MA: MIT Press.

Portner, Paul. 1998. The progressive in modal semantics. Language 74(4). 760-787. doi:https://www.jstor.org/stable/417002.

Reichenbach, Hans. 1947. Elements of Symbolic Logic. New York: Macmillan.

Rimell, Laura. 2004. Habitual sentences and generic quantification. In Vineeta Chand, Ann Kelleher, Angelo J. Rodríguez \& Benjamin Schmeiser (eds.), West 
Coast Conference on Formal Linguistics (WCCFL) 23, 663-676. Somerville, MA: Cascadilla Press.

Schein, Barry. 1993. Plurals and Events. Cambridge, MA: MIT Press.

von Stechow, Arnim. 2009. Tenses in compositional semantics. In Wolfgang Klein \& Ping Li (eds.), The Expression of Time, 129-166. Berlin: Mouton de Gruyter. Taylor, Barry. 1985. Modes of Occurrence: Verbs, Adverbs and Events. Oxford: Blackwell.

Thomas, Guillaume. 2015. The present tense is not vacuous. Journal of Semantics 32(4). 685-747. doi:https://doi.org/10.1093/jos/ffu010.

Sascha Alexeyenko

Department of English Linguistics

University of Göttingen

Käte-Hamburger-Weg 3

37073 Göttingen, Germany

sascha.alexeyenko@uni-goettingen.de 